\title{
ELECTROCATALYTIC OXIDATION AND VOLTAMMETRIC DETERMINATION OF SULFAMETHAZINE USING A MODIFIED CARBON ELECTRODE WITH IONIC LIQUID
}

\author{
L. URZÚA, M. PÉREZ-ORTIZ, A. ÁLVAREZ-LUEJE*
}

Chemical and Pharmaceutical Sciences Faculty, University of Chile, PO Box 233, Santiago 1, Chile

\begin{abstract}
A carbon paste electrode was modified with the ionic liquid 1-methyl-3-octyl imidazolium hexafluorophosphate and it was applied for study the electrocatalytic oxidation and voltammetric determination of the drug sulfamethazine. The developed modified electrode was characterized using cyclic voltammetry and scanning electron microscopy. The oxidation of sulfamethazine at the surface of modified electrode occurs at lower potentials than that of an unmodified carbon paste electrode, and both an enhancement of the anodic peak current and a signal narrower and better defined with the modified electrode were observed. Accordingly, a method for the determination of sulfamethazine was developed using differential pulse voltammetry, at $\mathrm{pH} 11$ and with an accumulation time of 3 min. The oxidation of sulfamethazine exhibited a dynamic range between 30 and $300 \mu \mathrm{g} / \mathrm{mL}$ and detection and quantitation limits of 54 and $61 \mu \mathrm{g} / \mathrm{mL}$, respectively. The method was applied to the determination of sulfamethazine in a veterinary commercial solution.
\end{abstract}

Keywords: Sulfamethazine, carbon paste, ionic liquid, modified electrodes, voltammetry

\section{INTRODUCTION}

Sulfamethazine,

4-amino- $N$-(4,6-dimethyl-2-pyrimidinyl) benzenesulfonamide, (Fig. 1) is a sulfonamide antibacterial widely used in veterinary ${ }^{1}$. Sulfamethazine blocks the synthesis of dihydrofolic acid by inhibiting dihydropteroate synthase. Besides, sulfamethazine is a structura analog and competitive antagonist of para-aminobenzoic acid (PABA) and can inhibit normal bacterial utilization of PABA for the synthesis of folic acid, which is an important metabolite in DNA synthesis ${ }^{2,3}$.

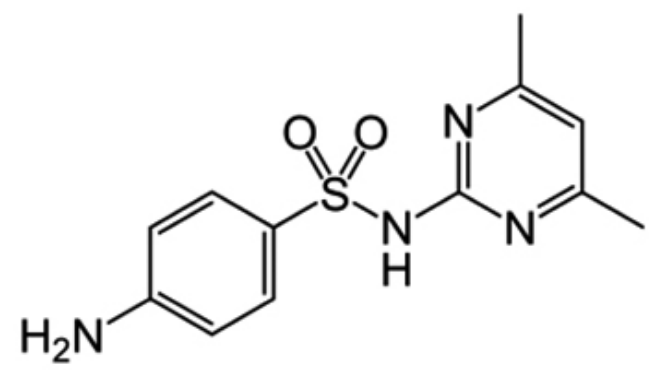

Figure 1. Chemical structure of sulfamethazine.

Different analytical methods for the quantitative determination of sulfonamides, including sulfamethazine have been developed ${ }^{4}$, as biosensors $^{5}$, high-performance liquid chromatography (HPLC) coupled to different detectors ${ }^{6-8}$, molecularly imprinted solid-phase microextraction and electrochemical methods, among them amperometric detection ${ }^{10,11}$, flow electrolysis on high surface electrode ${ }^{12}$ and by using modified carbon electrodes ${ }^{13-16}$

In the best of our knowledge, up to now methods based on carbon paste modified with ionic liquid electrode have not been reported for the study and determination of sulfamethazine.

Ionic liquids (IL) had been widely used in electroanalysis for the preparation of modified electrodes due to the good ionic conductivity and wide electrochemical windows. Due to better conductivity of IL compared with paraffin oil, they are proper for the preparation of carbon paste electrodes (CPE), because they reduce the charging current and improve sensitivity and detection limit ${ }^{17-19}$

According to the above, in the present work we constructed and characterized a CPE modified with the IL 1-methyl-3-octyl imidazolium hexafluorophosphate to be applied to the study of the electrochemical behavior of sulfamethazine and also to develop a differential pulse voltammetric method to determine this drug in dosage form.

\section{EXPERIMENTAL}

\section{Apparatus}

Cyclic voltammetry (CV) and differential pulse voltammetry (DPV) experiments were performed using a multichannel CHI 1030A potentiostat (CH Instruments, Inc., Austin, USA) controlled by a computer with 1030B CHI software. A 3-electrode system was used containing a CPE or a modified CPE $(\Phi=3.5 \mathrm{~mm})$ as the working electrode, a Pt wire as the counter electrode and an $\mathrm{Ag} / \mathrm{AgCl}$ electrode as the reference. Scanning electron microscopy (SEM) was performed on a FEI Inspect F50 (FEI Company, Japan). All experiments were performed at room temperature.

HPLC measurements were carried out by using a Jasco assembly equipped with a controller pump (PU-2089S), a column oven (CO-2060) and a photodiode array detector (MD-2018). The data acquisition was performed by ChromNav software. Chromatography was performed on Kinetex-Phenomenex reversedphase (Torrance, CA, USA) C-18 column at $25{ }^{\circ} \mathrm{C}$, a $20 \mu \mathrm{L}$ injection loop (Rheodyne valve) and a UV detector set at $264 \mathrm{~nm}$.

\section{Chemicals and solutions}

Graphite powder (Fisher ChemAlert), sulfamethazine $\quad(99.0 \%$, Veterquímica laboratory, Santiago, Chile), 1-methyl-3-octyl imidazolium hexafluorophosphate $(>97.0 \%$, Aldrich), ferrocene-methanol, potassium ferricyanide and hexaammineruthenium (III) chloride from Sigma, mineral oil (IR spectroscopy grade, Sigma-Aldrich). Methanol and ammonium acetate HPLC grade were obtained from Merck. All other reagents used were of proanalysis quality and all solutions were prepared with water obtained from a Milli-Q ultra-pure water purification system.

\section{Preparation of the solutions}

Buffer solutions. A 0.1 M Britton-Robinson buffer (an acetic, boric and phosphoric acid mixture) was used. The desired $\mathrm{pH}$ was adjusted by the addition of concentrated $\mathrm{NaOH}$ or $\mathrm{HCl}$ solutions.

Stock drug solutions. Standard stock solution of sulfamethazine were prepared daily at a constant concentration of $1 \times 10^{-2} \mathrm{M}$ in $0.1 \mathrm{M}$ BrittonRobinson buffer. This solution was protected from light and stored in amber glass containers

Work solutions. Stock standard solution of sulfamethazine was diluted with 0.1 M Britton-Robinson buffer to prepare working solutions of concentrations ranging from $1 \times 10^{-3} \mathrm{M}$ to $1 \times 10^{-5} \mathrm{M}$. The $\mathrm{pH}$ was adjusted with small aliquots of concentrated $\mathrm{NaOH}$ or $\mathrm{HCl}$.

Construction of carbon paste electrode (CPE) and modified CPE with ionic liquid (CPE-IL)

Carbon paste (CP) was prepared by hand-mixing paraffin oil and graphite powder in a ratio of 70/30 graphite/paraffin oil (w/w). The CPE-IL was fabricated by a similar procedure by adding different percentages of IL (w/w) to $\mathrm{CP}$. The paste was packed into the cavity of a Teflon tube $(3.5 \mathrm{~mm}$ diameter) An electrical contact was established via a copper wire inserted through the opposite end. Prior to use, a mirror-like surface was obtained by smoothing the 
electrode on a weighing paper.

\section{Analytical procedure}

Calibration curve preparation. Working solutions ranging from $30 \mu \mathrm{g} /$ $\mathrm{mL}-300 \mu \mathrm{g} / \mathrm{mL}$ were prepared by diluting the sulfamethazine stock solution with $0.1 \mathrm{M}$ Britton-Robinson buffer.

Assay procedure. $2.0 \mathrm{~mL}$ of Azovetril ${ }^{\circledR}$ (Veterquímica laboratory, Chile, amount declared $10 \%$ sulfamethazine and $2 \%$ trimethoprim) was mixed with 0.1 M Britton-Robinson buffer solution $\mathrm{pH} 11$ and diluted to a final volume of $10 \mathrm{~mL}$ with the same solvent. Then, the sample solution was transferred to a voltammetric cell and recorded at least twice from 400 to $1200 \mathrm{mV}$. The amount of sulfamethazine in the sample solution was calculated using the calibration curve.

\section{RESULTS AND DISCUSSION}

\section{Electrode characterization}

Figure 2 shows the SEM image of a CP film and a CP-IL film. Figures 2A and $2 \mathrm{~B}$ show a clear difference in uniformity and agglutination in both pastes. In the $\mathrm{CP}$ a more uniform surface is observed being flatter and smoother, while the surface appears more disaggregated, in an irregular way and with grooves in the CP-IL. Therefore the CP-IL presents greater agglomeration and grooves on the surface, that is, it is constituted by a larger interstitial surface that will affect the amount of electroactive area available on the surface of the electrode.
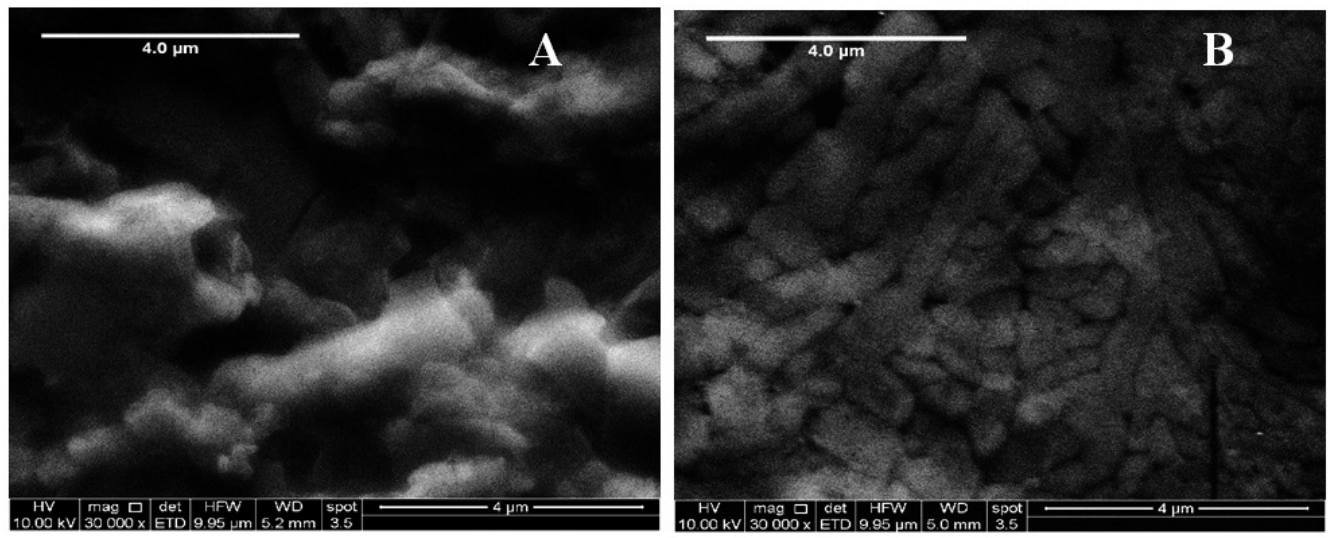

Figure 2. SEM images of the CP (A), CP-IL (B). Accelerating voltage: $10 \mathrm{keV}$, magnification: $30000 \times$

The modified electrode was characterized using CV to determine the behavior of the redox mediators ferrocenemethanol and potassium ferricyanide. Figure $3 \mathrm{~A}$ and $3 \mathrm{~B}$ present the cyclic voltammograms of $\mathrm{Fe}(\mathrm{CN}){ }_{6}^{3-} / \mathrm{Fe}(\mathrm{CN})_{6}^{4-}$ and the ferrocene/ferricinium redox couples obtained with the CPE and CPEIL. The voltammograms exhibit well-defined peaks and an increase in both the anodic $\left(\mathrm{Ip}_{\mathrm{a}}\right)$ and cathodic $\left(\mathrm{Ip}_{\mathrm{c}}\right)$ currents as the electrode was modified for both mediators. The greatest difference was obtained with the CPE-IL, which exhibited improved electrocatalytic activity compared to the unmodified electrode, thus confirming the effect of the IL reported by several authors ${ }^{20}$. On the other hand, the effect of IL on peak to peak separations $(\Delta \mathrm{Ep})$ is pronounced for the ferrocene/ferricinium redox couple (Fig. $3 \mathrm{~B}$ ) where the IL increases the reversibility $\left(\Delta \mathrm{Ep}_{\mathrm{CPE}-\mathrm{IL}}=142\right.$ vs $\left.\Delta \mathrm{Ep}_{\mathrm{CPE}}=497 \mathrm{mV}\right)$.

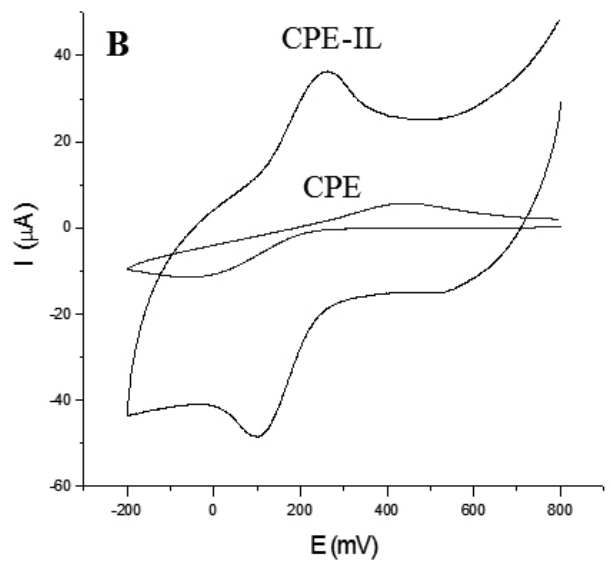

Figure 3. Cyclic voltammograms of potassium ferricyanide (A) and ferrocenemethanol (B) using CPE and CPE-IL. Britton-Robinson buffer solution (pH 7.4), scan rate: $100 \mathrm{mV} / \mathrm{s}$.

The electrochemically effective surface areas were calculated using a chronocoulometric method with a $1 \mathrm{mM} \mathrm{K}_{3}\left[\mathrm{Fe}(\mathrm{CN})_{6}\right]$ solution containing 0.1 $\mathrm{M} \mathrm{KCl}$, according to the Anson equation ${ }^{21}$ :

$$
\mathrm{Q}(t)=\frac{2 n F A C D^{1 / 2} t^{1 / 2}}{\pi^{1 / 2}}+Q_{d l}+Q_{a d s}
$$

in which $\mathrm{A}$ is the surface area of the working electrode, $\mathrm{C}$ is the concentration of the substrate, $\mathrm{D}$ is the diffusion coefficient $\left(7.6 \times 10^{-6} \mathrm{~cm}^{2} \mathrm{~s}\right.$ $\left.{ }^{1}\right)^{22}, \mathrm{Q}_{\mathrm{dl}}$ is the double-layer charge which could be eliminated via background subtraction, and $\mathrm{Q}$ is the Faradaic charge.

A solution of $1 \mathrm{mM}$ potassium ferricyanide was measured with the modified electrode by chronocoulombimetry. These results show that the electrode's effective surface area in CPE-IL increased 8.5 fold after modification (20.6 $\mathrm{cm}^{2}$ vs $175 \mathrm{~cm}^{2}$ ), increasing the current response and diminishing the detection limit. 
Electrochemical behavior of sulfamethazine on CPE-IL

By using DPV, sulfamethazine exhibits a well-defined and irreversible anodic signal on the CPE-IL over a broad $\mathrm{pH}$ range ( $\mathrm{pH} 2-10)$ (Fig. 4).

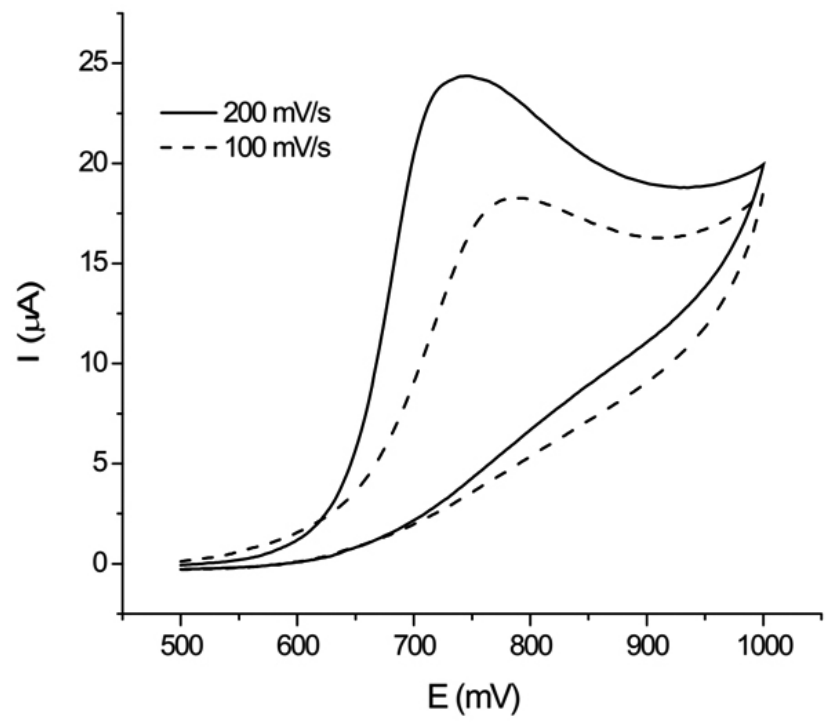

Figure 4. Cyclic voltammograms of $1 \mathrm{mM}$ sulfamethazine solution at different sweep rates.

The oxidation signal of sulfamethazine appears $\mathrm{pH}-$ dependent and is shifted toward lower anodic potentials as the $\mathrm{pH}$ increases, facilitating the oxidation process (Fig. 5). The Ep-pH plot exhibits two linear zones with slopes of 53.5 and $10.8 \mathrm{mV} / \mathrm{pH}$ and a break at $\mathrm{pH} 7.2$ (Fig. 6). This break is due to changes in the protonation-deprotonation equilibrium related to $\mathrm{pK}_{\mathrm{a}}$ of the molecule, reported as $7.4^{23,24}$. In contrast, peak current decreases only slightly as the $\mathrm{pH}$ increases with a minimum at $\mathrm{pH} 7$ and then go back up (inset on Fig. 6). For analytical purposes $\mathrm{pH} 11$ was selected due to that a better repeatability ( $3 \%$ coefficient of variation) was obtained.

In Figure 7, the DPVs of sulfamethazine at $\mathrm{pH} 5$ in both the CPE and CPEIL are shown. The peak current is shown to increase nearly 10 fold; this effect could be due to the accumulation of sulfamethazine and the increase in the electrocatalytic activity of the modified electrodes previously observed with the redox mediators.

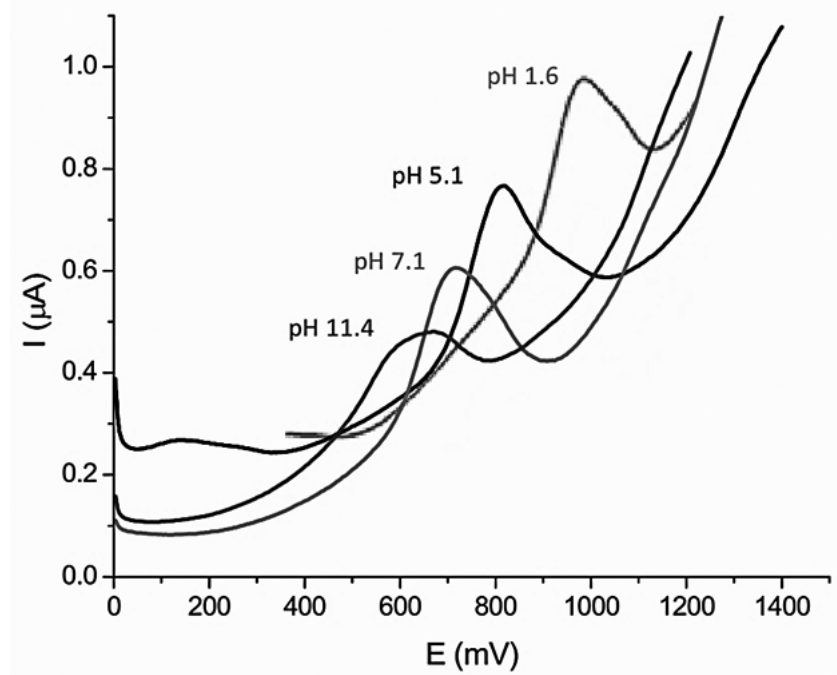

Figure 5. DPVs of a $1 \times 10^{-4} \mathrm{M}$ sulfamethazine solution at different $\mathrm{pHs}$ in $0.1 \mathrm{M}$ Britton-Robinson buffer.

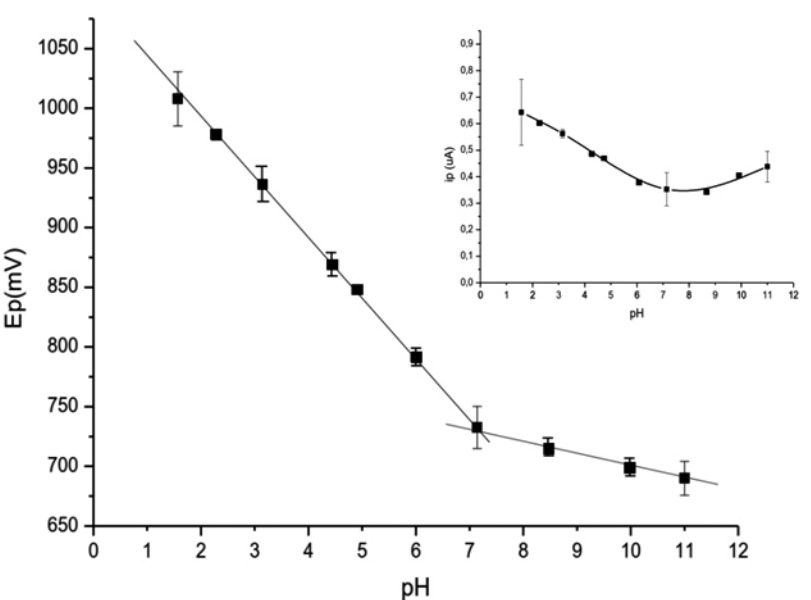

Figure 6. Peak potential evolution of a $1 \times 10^{-4} \mathrm{M}$ sulfamethazine solution at different pHs in $0.1 \mathrm{M}$ Britton-Robinson buffer. Inset: peak current (Ip) $v s$. $\mathrm{pH}$ graph.

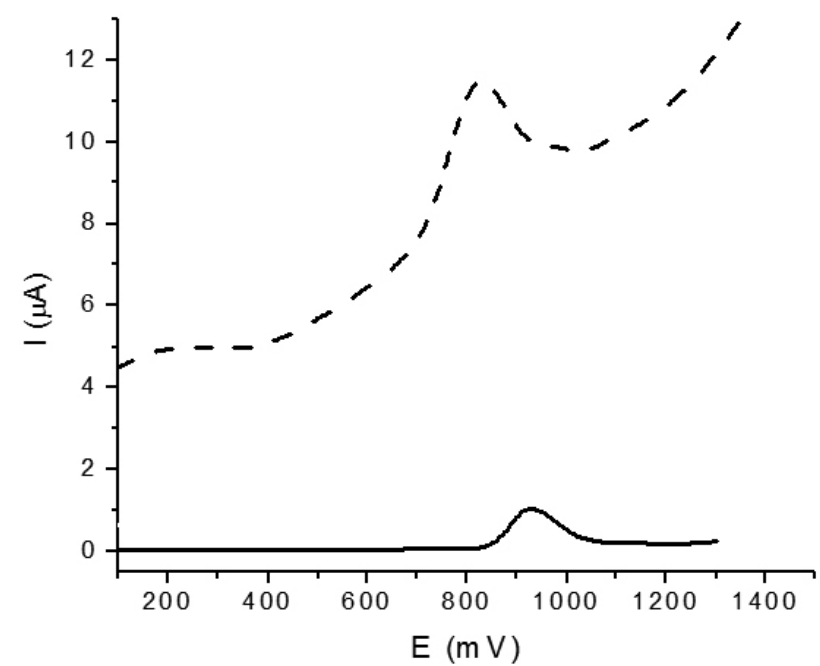

Figure 7. DPVs of a $1 \times 10^{-4} \mathrm{M}$ sulfamethazine solution $\mathrm{pH} 5$ at $\mathrm{CPE}$ (solid line) and CPE-IL (dashed line).

\section{Analytical Characterization}

To optimize the experimental conditions for determining sulfamethazine, an accumulation study by stirring was carried out. As shown in Figure 8, the solution required stirring for $3 \mathrm{~min}$ at $500 \mathrm{rpm}$ to achieve a maximum peak current and good repeatability

\section{Analytical Development}

Under the optimized conditions ( $\mathrm{pH} \mathrm{11,3}$ min accumulation time), a concentration study was carried out over a broad concentration range, obtaining a linear response between 30 and $300 \mu \mathrm{g} / \mathrm{mL}$. The detection (LOD) and quantitation limits (LOQ) of the method were calculated using the average $\left(Y_{b}\right)$ and standard deviations $\left(\sigma_{b}\right)$ of the blank estimated response, the slopes of the calibration curve $(\mathrm{m})$ and signal/noise ratios of 3 and 10 according to the following expressions ${ }^{25}$ :

$$
L O D=\frac{Y_{b}+3 \sigma_{b}}{m} \quad L O Q=\frac{Y_{b}+10 \sigma_{b}}{m}
$$

The within-day and inter-day reproducibilities of the seven independent electrodes were considered adequate for a modified electrode, with coefficients of variation below $5.7 \%$. Table 1 summarizes the analytical parameters, highlighting the wide range of linearity and low LOD and LOQ achieved. Taking into account that veterinary formulations of sulfamethazine ranging from 10 to $30 \%(\mathrm{w} / \mathrm{v})$, the obtained LOD is enough to apply the developed method to quantify sulfamethazine in this type of pharmaceuticals. 


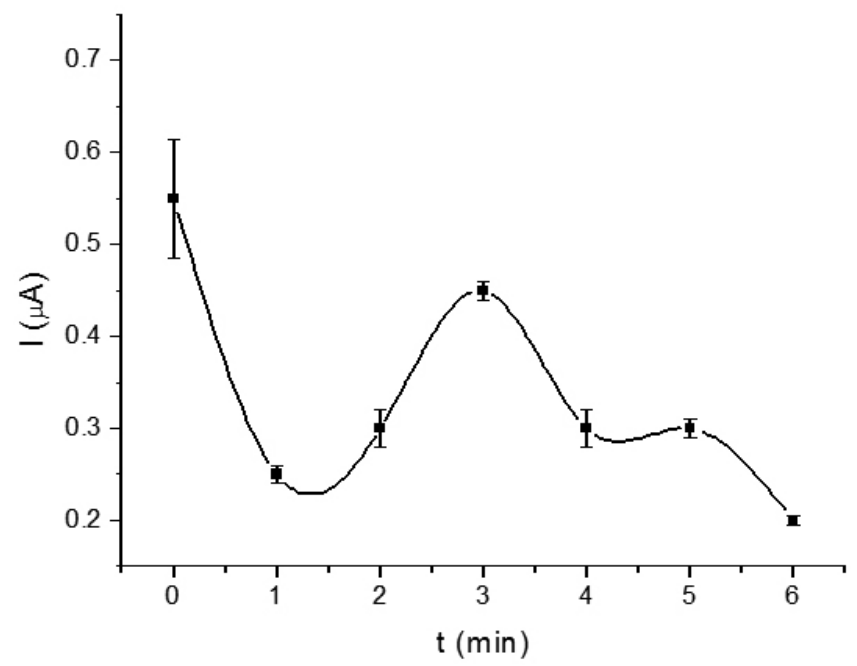

Figure 8. Peak current evolution with time accumulation (500 rpm) for $1 \times 10^{-4} \mathrm{M}$ sulfamethazine solution at $\mathrm{pH} 11$.

Finally, the developed DPV method was applied successfully to the assay of sulfamethazine in presence of trimethoprim in a commercial veterinary solution, and as comparative purposes also a HPLC assay was carried out ${ }^{26}$. The results for the assay of sulfamethazine were found to be $94.0 \% \pm 0.7$ $\%$ over the declared amount for DPV, and $95.7 \% \pm 0.2 \%$ over the declared amount for HPLC, and no interference of both excipients and trimethoprim was detected.

Table 1. Analytical parameters for the DPV method for sulfamethazine quantitation using a CPE-IL.

\begin{tabular}{|c|c|}
\hline Parameter & DPV $(\mathrm{E} \approx 0.7 \mathrm{~V})$ \\
\hline Within-day reproducibility, CV $(\%)$ & 3.6 \\
\hline Inter-day reproducibility, CV $(\%)$ & 5.7 \\
\hline Calibration curve $(\mathrm{Ip}, \mu \mathrm{A} ; \mathrm{C}, \mathrm{mg} / \mathrm{mL})$ & $\begin{array}{c}\mathrm{I}=11.96 \times \mathrm{C}+0.99\left(\mathrm{r}^{2}=0.999\right) \\
(\mathrm{n}=7)\end{array}$ \\
\hline Concentration range $(\mathrm{mg} / \mathrm{mL})$ & $0.03-0.3$ \\
\hline Detection limit $(\mu \mathrm{g} / \mathrm{mL})$ & 54 \\
\hline Quantitation limit $(\mu \mathrm{g} / \mathrm{mL})$ & 61 \\
\hline Recovery $(\%)$ & 98.4 \\
\hline
\end{tabular}

\section{CONCLUSIONS}

A stable, sensitive and reproducible CPE modified with the IL 1-methyl-3octyl imidazolium hexafluorophosphate was developed. This electrode proved an effective electrocatalyst for determining sulfamethazine compared with an unmodified CPE. From an analytical point of view, the use of this modified electrode allows the development of a DPV method to quantify sulfamethazine with good reproducibility. The simplicity of this voltammetric method allowed the quantification of sulfamethazine in a commercial solution without sample treatment.

\section{ACKNOWLEDGEMENTS}

The authors are grateful for the support of FONDECYT Grant No. 1150861 .

\section{REFERENCES}

1.- C.M. Kahn, S. Line; Merck \& Co. The Merck veterinary manual. Whitehouse Station, N.J.: Merck \& Co., 2010.

2.- J.F. Prescott, J.D. Baggott, editors. Antimicrobial therapy in veterinary medicine, 2nd ed. Ames, IA: Iowa State University Press, 1993. p. 119-26. 3.- J. Appelgate, Mod. Vet. Pract. 667 (1983).

4.- S.G. Dmitrienko, E.V. Kochuk, V.V. Apyari, V.V. Tolmacheva, Y.A. Zo- lotov, Anal. Chim. Acta 850, 6 (2014).

5.- E. Valera, A. Muriano, I. Pividori, F. Sánchez-Baeza, M.P. Marco, Biosens. Bioelectron. 43, 211 (2013).

6.- G.-F. Pang, Y.-Z. Cao, C.-L. Fan, J.-J. Zhang, X.-M. Li, Z.-Y. Li, G.-Q. Jia, Anal. Bioanal. Chem. 376, 534 (2003).

7.- S. Su, M. Zhang, B. Li, H. Zhang, X. Dong, Talanta 76, 1141 (2008).

8.- C.-K. Tsai, C.-S. Lin, W.-H. Wang, J. Food Drug Anal. 20, 674 (2012).

9.- S. Ansari, M. Karimi, Talanta 164, 612 (2017).

10.- H. Sangjarusvichai, W. Dungchai, W. Siangproh, O. Chailapakul, Talanta 79, 1036 (2009)

11.- T.N. Rao, B.V. Sarada, D.A. Tryk, A. Fujishima, J. Electroanal. Chem. 491, 175 (2000).

12.- I. Saidi, I. Soutrel, F. Fourcade, A. Amrane, D. Floner, N. Bellakhal, F. Geneste, J. Electroanal. Chem. 707, 122 (2013).

13.- I. Cesarino, R. Plana Simões, F.C. Lavarda, A. Batagin-Neto, Electrochim. Acta 192, 8 (2016)

14.- T.A.M. Msagati, J.C. Ngila, Talanta 58, 605 (2002).

15.- A. Guzman-Vazquez de Prada, A.J. Reviejo, J.M. Pingarrón, J. Pharm. Biomed. Anal. 40, 281 (2006).

16.- Y.L. Su, S.H. Cheng, Talanta 180, 81 (2018).

17.- A. Afkhami, H. Bagheri, A. Shirzadmehr, H. Khoshsafar, P. Hashemi, Electroanalysis 24, 2176 (2012).

18.- X. Yu, Y. Chen, L. Chang, L. Zhou, F. Tang, X. Wu, Sens. Actuators B 186, 648 (2013)

19.- W. Sun, Y. Wang, Y. Zhang, X. Ju, G. Li, Z. Sun, Anal. Chim. Acta 751, 59 (2012).

20.- B.N. Chandrashekar, B.E. Kumara Swamy, N.B. Ashoka, M. Pandurangachar, J. Mol. Liq. 165, 168 (2012).

21.- F. Anson, Anal. Chem. 36, 932 (1964).

22.- R. Adams, Electrochemistry at Solid Electrodes, Marcel Dekker, New York, 1969.

23.- Ș. Nurullah, Ș. Senem, Ö. Güleren, A. Denizlic, J. Braz. Chem. Soc 21,1952 (2010).

24.- J. Riviere, A.L. Craigmill, S.F. Sundlof, Handbook of comparative pharmacokinetics and residues of veterinary antimicrobials. Boca Raton, FL: CRC Press, Inc., 1991. p. 339-407.

25.- O.A. Quattrochi, S. A. De Andrizzi, R. F. Laba, Introducción a la HPLC, Aplicación y Práctica, Artes Gráficas Farro, SA, Argentina 1992.

26.- B. Cancho Grande, M.S. García Falcón, M. Rodríguez Comesaña, J. Simal Gándara, J. Agric. Food Chem. 49,3145 (2001). 